\title{
Influence of Job Characteristics on Job Stress: Mediation Effect of Job Ethics and Job Engagement
}

\author{
YoungMok Kim ${ }^{1}$, HeeJung Lee ${ }^{2}$ and Sela Lim $^{3 *}$ \\ ${ }^{1}$ Department of Clinical Psychology, NungIn University, Paltan-myeon, Hwaseong-si, \\ Gyeonggi-do, Korea \\ ${ }^{2}$ Department of Naturopathic, Dongbang Culture University, Seongbuk-gu, Seoul, \\ Korea \\ ${ }^{3}$ Department of Clinical Psychology, NungIn University, Paltan-myeon, Hwaseong-si, \\ Gyeonggi-do, Korea \\ 1ymkim3102@naver.com, ${ }^{2}$ anahjlee57@naver.com, ${ }^{3 *}$ sera325@nate.com
}

\begin{abstract}
This study explored correlation of $K$ pharmaceutical company's Staff for job characteristics and job stress to confirm mediation model and path of job ethics and job engagement. To this end, data was collected from 366 survey results conducted by 370 . The survey consisted of, the job characteristics scale and job stress scale, job ethics scale and job engagement scale. The results were analyzed by SPSS 22.0 program. To verify average and standard deviation of variables and mediation model of how job characteristics to job stress through, job ethics and job engagement the author used bootstrapping methods. For the research result, this study presented descriptive statics for each variable of respondents' and conducted correlation analysis among job characteristics to job stress through job ethics and job engagement ( $\beta=-.063, C . I[-.103 \sim-.031])$. And job characteristics to job stress through job ethics ( $\beta=.080$, C.I[.032 .137]). And job characteristics to job stress through job engagement $(\beta=-.253$, C.I[-.323 .185]). And job characteristics to job stress $(\beta=-.226$, C.I[-.312 -.140]).
\end{abstract}

Keywords: Job characteristics, Job stress, Job ethics, Job engagement

\section{Introduction}

At the modern society occupational schemes have come under pressure from rising costs and increasing complexity. Examples of common job stressors include work overload, role problems, poor job control, lack of support from supervisors and coworkers, and interpersonal conflicts.

It is the bane of the modern world. These stressors may lead to negative psychological (e.g., depression, irritability, and burnout), physical (e.g., headaches, heart palpations, and hyperventilation), and behavioral (e.g., absenteeism, turnover, and violence) symptoms or "strain sensation."

The psychological process that is involved in dealing with these job stressors in order to reduce strain is called "coping mechanism."

Article history:

Received (January 8, 2020), Review Result (February 14, 2020), Accepted (April 6, 2020) 
More specially, coping with job stress refers to the mental and behavioral strategies that employees use to handle the stressors they encounter at work.

Coping mechanism with job stress is a key concept in understanding people's adaptation to their job characteristics.

When job stress becomes increasingly difficult to control, it often leads to job characteristics [1], job stress [2], job ethics [3] and job engagement [4]. Therefore we have to conceptualize the role of ethical leaders in regard to the psychological intervention about job model.

There seem to be basically two answers. First, people's work because they want to overcome psychological or cognitional problems: job as a means for modification of job ethics.

Second, people's work to achieve a better understanding of job engagement for their job life.

These two aims often cannot be clearly separated, and most practitioners of job probably pursue both to a certain extent. People who have undergone extensive job training for job characteristics and job stress have shown improvements on cognitive performance in job ethics and job engagement.

Despite the public's growing interest and an increasing number of studies on the impact of job characteristics and job stress, there is a surprising scarcity of summaries of the empirical evidence, especially for evidence that stems from research outside the therapeutic context within job ethics and job engagement.

Numerous studies have been conducted to search for effects of fields of pharmaceutical company's Staff of study, yet there is an even more surprising lack of elaborate psychological theories that make sound predictions about what to expect if one works.

This a theoretical approach is frequently mirrored in the measures used in the studies, which include all kinds of dependent variables that are not specific to work (job characteristics and job stress) research and have also been used in many other kinds of research.

Although, in this article, we place an emphasis on empirical evidence, we are convinced that real progress in understanding the effects of job characteristics and job stress cannot be made if future empirical studies are not guided by better theories.

Therefore, after briefly surveying previous attempts to summarize the literature on the effects of job characteristics, job stress, job ethics and job engagement, we introduce existing theoretical approaches from the South Korea. Following our analysis of the empirical evidence, we return to the issue of how we might make progress in understanding job characteristics, job stress, job ethics and job engagement and its effects. However, job characteristics and job stress perceived as positive cognition based on unconscious critical thoughts. It also causes psychological confusion and psychopathology. Kim reported the results of a positive correlation between job ethics and job engagement[4]. Furthermore, comparative studies of research or cognition types focusing on psychological intervention have reported that psychological intervention positively affects victims' mental health as well as job characteristics and job stress and, in some cases, has more positive and long-term effects than job ethics and job engagement. As a result, it is found that there is a lack of research on mediating effects of job characteristics, job stress, job ethics and job engagement.

Therefore, this study aims to investigate the relationship between characteristics and job stress, and job ethics and job engagement, and examines the mediating model between job ethics and job engagement between job characteristics and job stress. 
This study is based on the assumption that the issues of cognitional maladjustment due to various job characteristics and job stress experienced by meditator living of South Korea are related to job ethics and job engagement.

It would be useful for enhancing the understanding of the factors affecting the meditator, and could provide the opportunity for the clinician to provide basic data on research and psychotherapy.

\section{Methods}

\subsection{Subjects and data collection}

This study was conducted from July 2019 to August 2019, for those who participated in the male and Female in seoul of Korea. Finally, the data of total 366 participants were analyzed.

\subsubsection{Subjects of gender}

The gender of the participants is as follows [Table 1].

Table 1. Subjects of gender $(\mathrm{N}=366)$

\begin{tabular}{|c|c|c|}
\hline & $\mathrm{N}$ & $\%$ \\
\hline Males & 305 & 83.3 \\
\hline Females & 61 & 16.7 \\
\hline Total & 366 & 100 \\
\hline
\end{tabular}

\subsubsection{Subjects of age}

The age of the participants is as follows [Table 2].

Table 2. Subjects of age $(\mathrm{N}=366)$

\begin{tabular}{|c|c|c|}
\hline age & N & $\%$ \\
\hline $20-29$ & 36 & 9.8 \\
\hline $30-39$ & 204 & 55.7 \\
\hline $40-49$ & 114 & 31.1 \\
\hline $50-59$ & 11 & 3 \\
\hline $60-69$ & 1 & 0.3 \\
\hline Total & 366 & 100 \\
\hline
\end{tabular}

\subsubsection{Subjects of position}

The position of the participants is as follows [Table 3].

Table 3. Subjects of position $(\mathrm{N}=366)$

\begin{tabular}{|c|c|c|}
\hline & N & $\%$ \\
\hline Staff member & 89 & 24.3 \\
\hline Manager & 58 & 15.8 \\
\hline
\end{tabular}




\begin{tabular}{|c|c|c|}
\hline Deputy section Chief & 73 & 19.9 \\
\hline Section chief & 60 & 16.4 \\
\hline Chief & 56 & 15.3 \\
\hline Executives & 24 & 6.6 \\
\hline Contract Employee & 4 & 1.1 \\
\hline Missing value & 2 & 0.5 \\
\hline total & 366 & 100 \\
\hline
\end{tabular}

\subsubsection{Subjects of task}

The task of the participants is as follows [Table 4].

Table 4. Subjects of task $(\mathrm{N}=366)$

\begin{tabular}{|c|c|c|}
\hline & N & $\%$ \\
\hline Seles personnel & 235 & 64.2 \\
\hline Administrative position & 91 & 24.9 \\
\hline Research position & 12 & 3.3 \\
\hline Production & 18 & 4.9 \\
\hline The others & 10 & 2.7 \\
\hline Total & 366 & 100 \\
\hline
\end{tabular}

\subsubsection{Subjects of employment period}

The employment period of the participants is as follows [Table 5].

Table 5. The employment period of the participants $(\mathrm{N}=366)$

\begin{tabular}{|c|c|c|}
\hline & N & $\%$ \\
\hline Less than three years & 65 & 17.8 \\
\hline Less than five years & 66 & 28.7 \\
\hline Less than ten years & 105 & 22.7 \\
\hline Less than fifteen years & 83 & 9.8 \\
\hline Less than twenty years & 36 & 1.6 \\
\hline Less than twenty -fifth years & 6 & 1.1 \\
\hline Less than thirty years & 4 & 0.3 \\
\hline More than thirty years & 1 & 100 \\
\hline Total & 366 & \\
\hline
\end{tabular}

\subsubsection{Subjects of annual income}

The annual income of the participants is as follows [Table 6]. 
Table 6. Subjects of annual income $(\mathrm{N}=366)$

\begin{tabular}{|c|c|c|}
\hline & N & $\%$ \\
\hline Less than $25.000 \$$ & 35 & 34.4 \\
\hline Less than $42.000 \$$ & 126 & 30.6 \\
\hline Less than $50.000 \$$ & 112 & 18.9 \\
\hline Less than 58.000\$ & 69 & 4.6 \\
\hline Less than 75.000 & 17 & 1.6 \\
\hline More than90.000\$ & 6 & 0.3 \\
\hline Missing value & 1 & 100 \\
\hline Total & 366 & 17 \\
\hline
\end{tabular}

\subsection{Measurement}

\subsubsection{Job characteristics}

In order to measure job characteristics, we used the Job Characteristics Questionnaire (JCQ), which was developed by Hackman and Oldham [5]. In the present study, the total of the job characteristics of Cronbach's $\alpha$ was .825 .

\subsubsection{Job stress}

In order to measure job stress, we used the Job Stress Questionnaire(JSQ), which was developed by Chang, Koh, Kang, Kim, Kang, Lee, Chung, Cho, Son, Chae, Kim, Kim, Kim, Roh, Park, Woo, Kim, Kim, Ha, Park, Rhee, Kim, Kong, Kim, Kim, Park, Huyun, Son [6] and Chang [7]. In the present study, the total of the job stress of Cronbach's $\alpha$ was 896.

\subsubsection{Job ethics}

In order to measure job ethics, we used the Job Ethics Questionnaire (JEQ), which was developed by Kang [8]. In the present study, the total of the job ethics of Cronbach's $\alpha$ was .830.

\subsubsection{Job engagement questionnaire}

In order to measure job engagement, we used the Job Engagement Questionnaire(JIQ), which was developed by Kanugo [9] which was adapted by Kim [10]. In the present study, the total of the job engagement of Cronbach's $\alpha$ was .924 .

\subsection{Data analysis}

Data collected for this study were analyzed using the IBM SPSS V.22 as follows. We used a $95 \%$ confidence interval based on the empirical distribution estimated by bootstrapping to verify the mediating effect. Bootstrapping interpreted the sample as statistically significant if it did not know the distribution of the population and if the $95 \%$ confidence interval did not include zero [11][12].

\section{Results}




\subsection{Path model}

A job characteristics analysis was conducted to confirm the effects of job stress. Specifically, the job characteristics and job stress has a significant effect on the job ethics and engagement, In addition, the job characteristics was found to have a significant effect on job ethics $(\beta=.482, \mathrm{p}<.001)$, and the job characteristics was found to have a significant job engagement $(\beta=.460, p<.001)$, and the job characteristics was found to have a significant job $\operatorname{stress}(\beta=-.248, p<.001)$. A significant correlation was found between job ethics and job engagement $(\beta=.236, p<.001)$ and job stress $(\beta=.183, p<.001)$, and the job ethics was found to have a significant job stress $(\beta=-.605, p<.001)$ [Table 7].

Table 7. Path model

\begin{tabular}{|c|c|c|c|c|c|c|c|}
\hline \multicolumn{3}{|c|}{ Path } & B & $\beta$ & s.e & $t$ & $p$ \\
\hline \multirow{3}{*}{$\begin{array}{c}\text { job } \\
\text { characteristics }\end{array}$} & \multirow{3}{*}{$\rightarrow$} & job ethics & 0.441 & .482 & .042 & 10.488 & .000 \\
\hline & & job engagement & 0.558 & .460 & .058 & 9.680 & .000 \\
\hline & & job stress & -0.226 & -.248 & 0.44 & -5.161 & .000 \\
\hline \multirow{2}{*}{ job ethics } & \multirow{2}{*}{$\rightarrow$} & job engagement & 0.312 & .236 & .063 & 4.964 & .000 \\
\hline & & job stress & 0.182 & .183 & .044 & 4.130 & .000 \\
\hline $\begin{array}{c}\text { job } \\
\text { engagement }\end{array}$ & $\rightarrow$ & job stress & -0.454 & -.605 & .036 & -12.748 & .000 \\
\hline
\end{tabular}

\subsection{Measurement model}

We performed bootstrapping by extracting 2000 parts of the escapism of job characteristics to the job stress through the job ethics and job engagement.

As a result, the indirect effect was significant because the path through the job ethics and job engagement included 0 in the $95 \%$ confidence interval of the indirect effect $(\beta=-.226$, C.I[-.312 -.140]).

And As a result, the indirect effect was significant because the path through the job ethics included 0 in the $95 \%$ confidence interval of the indirect effect ( $\beta=.080$, C.I[.032 .137]).

And As a result, the indirect effect was significant because the path through the job engagement included 0 in the $95 \%$ confidence interval of the indirect effect ( $\beta=-.226$, C.I[.312 -.140]) [Table 8].

Table 8. Measurement model

\begin{tabular}{|c|c|c|c|c|c|c|c|}
\hline $\begin{array}{c}\text { Independent } \\
\text { variable }\end{array}$ & Parameter1 & Parameter2 & $\begin{array}{c}\text { Dependent } \\
\text { variable }\end{array}$ & $\begin{array}{c}\text { Total effec } \\
\text { [bootstrapping } \\
\text { CI 95\%] }\end{array}$ & $\begin{array}{c}\text { Direct effect } \\
\text { [bootstrapping } \\
\text { CI 95\%] }\end{array}$ & $\begin{array}{c}\text { Total indirect } \\
\text { effect } \\
\text { [bootstrapping } \\
\text { CI 95\%] }\end{array}$ & $\begin{array}{l}\text { Indirect effect } \\
\text { [bootstrapping } \\
\text { CI 95\%] }\end{array}$ \\
\hline $\begin{array}{c}\text { job } \\
\text { characteristics }\end{array}$ & job ethics & $\begin{array}{c}\text { job } \\
\text { engagement }\end{array}$ & job stress & $\begin{array}{c}-.461 \\
{[-.542 \sim-.381]}\end{array}$ & - & $\begin{array}{c}-.235 \\
{[-.306 \sim-.165]}\end{array}$ & $\begin{array}{c}-.063 \\
{[-.103 \sim-.031]}\end{array}$ \\
\hline
\end{tabular}




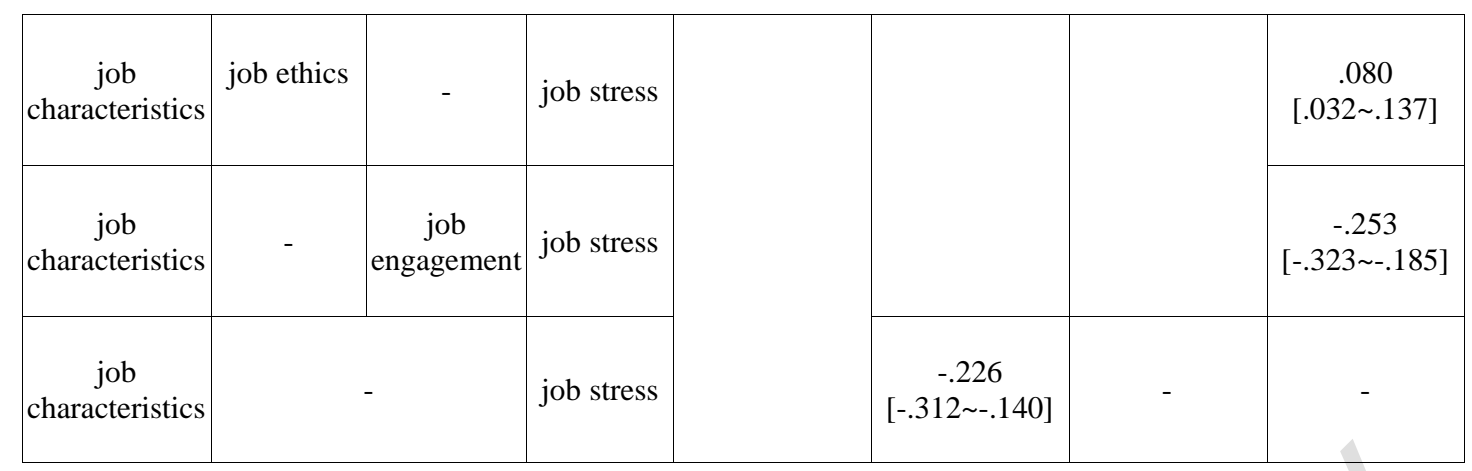

\section{Conclusions}

The results of this study suggest that job characteristics of K pharmaceutical company's Staff has a significant effect on job stress through the job ethics and job engagement.

Meanwhile, a simple correlation analysis, revealed that there was a significant correlation between job characteristics, job stress, job ethics and job engagement, whereas the path search for the median model analysis was significant.

This is consistent with a previous study, which reported a significant correlation between job characteristics, of people and job stress [13].

Lee [14] discovered that most causes of job characteristics that interfere with job ethics, is experienced in work life.

Kim [15] discovered among work experienced people that most of the causes of job characteristics that interfere with thinking are related to job engagement, individual cognitional healthy work style and experiences of job satisfaction in citizenship behavior.

Therefore, objective perception of changes in these cognition conditions could lead to a deterioration of psychological function.

In conclusion, the mediating effect of job characteristics, on job stress and the job ethics and job engagement of pharmaceutical company's Staff was solely analyzed in South Korea, and significant results were obtained. Nevertheless, it is important to note that results from this study could be used in reference to cognitional work style especially during counseling interventions and in clinical settings.

\section{References}

[1] R. J. Hackman and G. R. Oldham, "Work redesign,” Addison-Wesley, Florida, pp.56, (1980)

[2] S. H. Yoon, "The effects of organizational managerial characteristics and job characteristics on job stress and job effectiveness: A survey on clinical nurses," Korean Journal of Psychology: Industrial and Organizational Psychology, vol.17, no.3, pp.451-466, (2004)

[3] K. H. Roberts and W. Glick, "The job characteristics approach to task design: A critical review," Journal of Applied Psychology, vol.66, no.2, pp.193-217, (1981) DOI:10.1037/0021-9010.66.2.193

[4] J. H. Kim, "A study on factors influencing public service ethics of government officials," Ph.D. dissertation, Department of Public Administration, Graduate School of Konkuk University, (2013)

[5] J. R. Hackman, "Groups that work: Creating conditions for effective teamwork," Jossey-Bass, San Francisco, pp.126, (1980)

[6] S. J. Chang, S. B. Koh, D. M. Kang, S. A. Kim, M. G. Kang, C. G. Lee, J. J. Chung, J. J. Cho, M. A. Son, C. H. Chae, J. W. Kim, J. I. Kim, H. S. Kim, S. C. Roh, J. B. Park, J. M. Woo, S. Y. Kim, J. Y. Kim, M. N. Ha, J. S. Park, K. Y. Rhee, H. R. Kim, J. O. Kong, I. A. Kim, J. S. Kim, J. H. Park, S. J. Huyun, and D. K. Son, 
"Developing an occupational stress scale for Korean employees," Korean Journal of Occupational and Environmental Medicine, vol.17, no.4, pp.297-327, (2005) DOI:10.35371/kjoem.2005.17.4.297

[7] S. J. Chang, "Standardization of job stress measurement and assessment," Industrial Hygiene, vol.229, pp.1721, (2007)

[8] S. W. Kang, "A study on social factors influencing ethics in bureaucrats," Ph.D. dissertation, Department of Public Administration, The Graduate School, Dongyang University, (2017)

[9] R. N. Kanungo, "Work alienation and involvement: Problems and prospects," Applied Psychology, vol.30, no.1, pp.1-15, (1981) DOI:10.1111/j.1464-0597.1981.tb00976.x

[10] S. H. Kim, "A study on the effectiveness of job ability of aesthetician in national competency standard based education," Ph.D. dissertation, Department of Art and Craft, Graduate School of Konkuk University, (2018)

[11] A. F. Hayes, "Introduction to mediation, moderation, and conditional process analysis: A regression-based approach," The Guilford Publications, New York, pp.169, (2017)

[12] P. E. Shrout and N. Bolger, "Mediation in experimental and nonexperimental studies: New procedures and recommendations," Psychological Methods, vol.7, no.4, pp.422-445, (2002) DOI:10.1037/1082-989X.7.4.422

[13] G. O. Lee, "The effects of job characteristics on the job stress and job satisfaction: In case of Inflight attendants," M.S. thesis, The Graduate School of Business Administration, Korea Aerospace University, (2009)

[14] J. S. Lee, "A study on the enhancement of public officials' public service ethics consciousness," M.S. thesis, Department of Public Administration, The Graduate School of Public Administration, Chung-Ang University, (2011)

[15] K. K. Kim, "Influences of hotel employee's job characteristic on organization commitment and job satisfaction and organization citizenship behavior in the hotel corporation," vol.19, no.2, pp.469-488, (2006) 